\title{
Exercise training in patients with chronic heart failure: A new challenge for Cardiac Rehabilitation Community
}

\author{
Francesco Giallauria1, Lucrezia Piccioli1, Giuseppe Vitale², Filippo M. Sarullo² \\ 1 Department of Translational Medical Sciences, Division of Internal Medicine, Metabolic \\ and Cardiac Rehabilitation Unit, Federico II University of Naples \\ 2 Cardiovascular Rehabilitation Unit, Buccheri La Ferla Fatebenefratelli Hospital, Palermo, Italy
}

\begin{abstract}
Exercise training (ET) is strongly recommended in patients with chronic stable heart failure (HF). Moderate-intensity aerobic continuous ET is the best-established training modality in HF patients. In the last decade, however, high-intensity interval exercise training (HIIT) has aroused considerable interest in cardiac rehabilitation community. In HF patients, HIIT exerts larger improvements in exercise capacity compared to moderate-continuous ET. Since better functional capacity translates into symptoms relief and improvement in quality of life in patients with $\mathrm{HF}$, this training modality is collecting growing interest and consensus, not revealing major safety issues. HIIT should not replace other training modalities in HF but should rather complement them. Inspiratory muscle training, another promising training modality in patients with HF, exerts beneficial effect on inspiratory muscle strength and inspiratory endurance, on exercise capacity and quality of life. In conclusion, taking into consideration the complecity of HF syndrome, combining and tailoring different ET modalities according to each patient's baseline clinical characteristics (i.e., exercise capacity, comorbidity, frailty status, personal needs, preferences and goals) seem the wiliest approach for exercise prescription. The present re-
\end{abstract}

Corresponding author: Francesco Giallauria, Department of Translational Medical Sciences, Internal Medicine, Metabolic and Cardiac Rehabilitation Unit, Federico II University of Naples, Bldg. 18 1st floor, Via S. Pansini 5, 80131 Napoli, Italy. E-mail: francesco.giallauria@unina.it

Key words: Moderate-intensity aerobic continuous exercise training; high-intensity interval training; inspiratory muscle training; chronic heart failure; cardiac rehabilitation; exercise prescription.

Contributions: FG, FMS, study concept, manuscript drafting; bibliography revision; LP, GV, bibliographic research, contribution to the manuscript final version.

Received for publication: 10 August 2018

Accepted for publication: 3 September 2018

(C) Copyright F. Giallauria et al., 2018

Tipografia PI-ME Editrice, Italy

Monaldi Archives for Chest Disease 2018; 88:987

doi: 10.4081/monaldi.2018.987

This article is distributed under the terms of the Creative Commons Attribution Noncommercial License (by-nc 4.0) which permits any noncommercial use, distribution, and reproduction in any medium, provided the original author(s) and source are credited. view aims at discussing the rececent evidences on the effects of exercise training in patients with chronic HF (with both reduced and preserved left ventricular function).

\section{Introduction}

Heart failure (HF) is an exponentially growing epidemic syndrome leading to significant socio-economic burden, with a prevalence that reaches up to $10 \%$ among persons aged 70 years or older [1]. Despite impressive advances in the pharmacological treatment of HF, mortality and morbidity still remain a major concern [2], and frequent hospital admissions have a deleterious impact on daily life and social activities. European guidelines have incorporated a class IA recommendation for regular aerobic exercise in HF patients to improve functional capacity and symptoms relief [3-5]. Mechanisms underlying exercise-induced improvement in exercise tolerance are summarized in Table 1. Notably, the current therapeutic strategy, based on a titrated drug regimen and innovative electrical implantable devices still fails to ameliorate exercise tolerance [6,7]. Exercise training (ET) is considered one of the most effective interventions to improve cardiopulmonary functional capacity and patients' health status perception in patients with HF (either with reduced or preserved left ventricular ejection fraction) [3,5,8-16]. In people with both systolic HF and HF with preserved left ventriculr ejection fraction (HFpEF), cardiorespiratory fitness is impaired. Impaired peak oxygen consumption (peakV02) has been associated with increased mortality risk [17] and decreased quality of life in patients with HF. In addition, by using traditional echocardiograhic indices of measurement (left ventricular ejection fraction), systolic function appears largely normal under resting conditions in HFpEF. However, studies have shown through global assessment of systolic function by strain rate imaging, systolic abnormalities do exist in HFpEF patients [18]. Despite the preservation of resting systolic function, mortality rates in HFpEF are similar to those observed in systolic failure [19]. Apart from HF, ET efficacy is under active investigation in a wide range of cardiovascular, endocrine, and neurological disorders ranging from pulmonary hypertension, to Friedereich's ataxia, conditions of GH excess and deficiency, and Takotsubo cardiomyopathy [20-28].

The present review aims at discussing the rececent evidences on the effects of exercise training in patients with chronic HF (with both reduced and preserved left ventricular function).

\section{Pathophysiological effects of exercise training}

Exercise capacity depends on central cardiac, as well as peripheral mechanisms [29,30]. In fact, the correlation between peak oxygen consumption $\left(\mathrm{VO}_{2}\right.$ peak) and resting left ventricular ejection fraction (LVEF) is scarce in patients with HF. Therefore, cardiac reserve during 
exercise, together with peripheral vascular function, oxygen uptake and utilization (skeletal muscle), increased ergoreceptor activity; but ventilatory inefficiency should be accounted for [31,32].

In patients with HF, ET decreases circulating catecholamine levels [33,34], has anti-inflammatory [35,36] and antioxidative effects [37,38] reduces natriuretic peptide leves [39-42], exerting a reduction in peripheral vasoconstriction, an improvement of endothelial function and endothelial repair enhancement [32,43-45]. Regular ET also prevents muscle wasting and restores anabolic/catabolic imbalance [4648], as well as hyperactive muscle ergoreflexes [31,32]. These changes parallel observed training-induced increases in $\mathrm{VO}_{2}$ peak and exert beneficial effects on clinical outcomes [49].

In patients with $\mathrm{HFpHF}$, recent meta-analysis showed a significant improvement in peakV02 of $2.13 \mathrm{ml} / \mathrm{kg} / \mathrm{min}$ [95\% confidence interval (CI) 1.54 to 2.71, $\mathrm{P}<0.00001$ ] in exercise $v s$ control [16]. These data are in line with previous meta-analysis with a similar effect size seen previously [50]. Interestingly, the meta-analysis by Dieberg et al. [16] is the first to identify that exercise training may significantly improve diastolic function as evaluated by E/A ratio. Neither individual studies, nor pooled analyses published previously, have shown a post-exercise training benefit [50]. Moreover, this meta-analysis showed an exercise-induced improvement (small reduction) of E/E' which is a surrogate of filling pressure. Finally, the same meta-analysis [16] showed a significant reduction in deceleration time (DT). Taken together, these three measures of diastolic function have shown a trend toward normalization after ET. While exercise-induced improvement of diastolic function has been previously demonstrated in healthy people [51], previous work in HFpEF has failed to show a trend toward improved E/A and DT [52]. Further well-designed and appropriately powered studies on HFpEF cohort are required to provide evidence on the pathophysiological effects of ET on diastolic function improvement.

\section{Impact of exercise training on mortality}

Exercise training results in $35 \%$ lower risk for mortality and in $28 \%$ lower risk for the composite endpoint of mortality or hospitalization in the ExTraMATCH (Exercise Training for Chronic Heart Failure) collaborative group [53]. Another meta-analysis including 11 randomized controlled studies (RCTs) found a 39\% lower relative risk for mortality

Table 1. Pathophysiological mechanisms underlying exercise-induced improvement in exercise tolerance.

\section{Brain}

个Arterial baroreflex sensitivity/control

个Sympathoexcitation/vasoconstriction (gut/muscle/skin/general)

\section{Arteries}

$\uparrow$ Sympathovagal balance ( $\downarrow$ resting heart rate, $\uparrow$ heart rate recovery)

$\boldsymbol{\uparrow}$ Systemic arterial compliance, $\uparrow \mathrm{CPCs}$, $\boldsymbol{\uparrow}$ Endothelium-mediated vasodilation, $\boldsymbol{\uparrow}$ NO bioavailability, $\boldsymbol{\uparrow}$ tetraidrobiopterine $\left(\mathrm{BH}_{4}\right), \boldsymbol{\Downarrow} \mathrm{ROS}$,

$\boldsymbol{\Downarrow}$ Catecholamines, $\boldsymbol{\Downarrow}$ Endothelin-1, $\boldsymbol{\Downarrow}$ Angiotensin II, $\boldsymbol{\Downarrow}$ Arginine-vasopressin, $\boldsymbol{\Downarrow}$ BNP, $\boldsymbol{\Downarrow}$ NT-proBNP, $\boldsymbol{\Downarrow}$ Circulating cytokines

Inflammatory markers

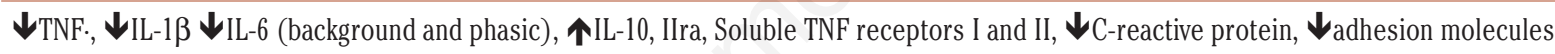
[Overall, exercise training exerts antinflammatory effect)

$\downarrow$ Vascular pressure/ $\boldsymbol{}_{\text {ventilation/perfusion mismatch }}$
$\downarrow$ Stiffness/ $\boldsymbol{\uparrow}$ Diffusion capacity
$\downarrow$ Pulmonary artery resistance/pressure
$\downarrow$ Alveolar-arterial $\mathrm{O}_{2}$ gradient
Respiratory muscle: $\downarrow$ Blood Flow, $\boldsymbol{V}_{2}$
Kidney
$\downarrow$ Sympathoexcitation/vasoconstriction
Heart
$\downarrow$ LV remodelling, LV size, LVEDP
$\boldsymbol{\uparrow}$ Ejection fraction, Stroke Volume, Maximal cardiac output, Endothelium-mediated coronary dilation
$\downarrow$ Total peripheral resistance
Muscle

个Blood flow, Capillaries per fiber, Mitochondrial volume/oxidative enzyme activity, $\mathrm{O}_{2}$ diffusing capacity, $\mathrm{O}_{2}$ delivery- $\mathrm{VO}_{2}$ matching,

NO availability and Endothelium-mediated vasodilation, Apoptosis/atrophy, Muscle pump

$\downarrow$ iNOS, Vascular stiffness, metaboreflex

All these changes contribute to increase speed $\mathrm{VO}_{2}$ kinetics $\left(\boldsymbol{\uparrow} \mathrm{VO}_{2} \max\right.$, Critical Power, Lactate Threshold, $\downarrow \mathrm{O}_{2}$ cost of exercise

\section{^ EXERCISE TOLERANCE}

BNP, brain natriuretic peptide; CPCs, circulating progenitor cells; HR, heart rate; LVEDP, left ventricular (LV) end-diastolic pressure; iNOS, inducible nitric oxide (NO) synthase; NO, nitric oxide; ROS, reactive oxygen species; $\mathrm{VO}_{2}$ max, maximum oxygen consumption. 
in the exercise group [54]. However, none of the RCTs included in these meta-analyses had sufficient power to address hard endpoints; and most of them were small single-centre trials. The HF-ACTION trial (Heart Failure - A Controlled Trial Investigating Outcomes of exercise TraiNing) is the largest recent multicentre RCT designed to measure the effects of exercise training on clinical outcomes and safety in patients with HF [55]. After a median follow-up time of 30 months, and after adjustment for predefined prognostic predictors, all-cause mortality or all-cause hospital stay were significantly reduced $(-11 \%, \mathrm{p}=0.03)$ in the training group. However, this trial was biased by a very low adherence level to exercise prescription regimen, resulting in a smaller than expected improvement in aerobic functional capacity. This issue reinforces the need for delineating new stretegies aimed at improving adherence to exercise-based cardiac rehabilitation programs [56,57].

\section{Exercise prescription}

The lack of clearly delineated practical guidelines for ET prescription determined a variety of centre-specific approaches for HF patients [58]. The exercise programmes may differ in terms of type (endurance, resistance and strength), intensity (aerobic $v s$ anaerobic); method (continuous vs intermittent/interval); setting (hospital/centrebased $v s$ home-based); application (systemic, regional and respiratory muscle) and control (supervised $v s$ nonsupervised) [58].

\section{Aerobic or endurance exercise training}

Aerobic or endurance training (i.e., cycling, walking, rowing) is the most adopted modality in patients with $\mathrm{HF}$, and is recommended as baseline activity [53,54,58-60]. Cycling is usually preferred because of the reproducible power output and reduced injury rate, and allow to exercise at low workloads.

In order to avoid exercise-related risks and adverse events, the maximum training intensity for HF patients is usually identified at the first ventilatory anaerobic threshold (VAT) (50-60\% of $\mathrm{VO}_{2}$ peak) [61,62]. However, taking into consideration that patients with HF need higher percentage of their $\mathrm{VO}_{2}$ peak (compared to normal subjects) to perform daily life activities [63-65], and since one of the main scopes of ET is allowing these patients to perform daily tasks with less effort; training intensities above the VAT have progressively been tested and introduced.

The respiratory compensation point $\left(65-90 \%\right.$ of $\mathrm{VO}_{2}$ peak) [66], which is the limit between high-intensity and severe-intensity effort ("critical power"), is now recognized as the limit for prolonged aerobic exercise without exposing to additional risk HF patients $[67,68]$. Currently, exercise intensities between $70-80 \%$ of $\mathrm{VO}_{2}$ peak are commonly prescribed $[69,70]$. Nevertheless, in HF patients with significantly lower pre-training $\mathrm{VO}_{2}$ peak and/or high exercise-related risks (more compromised and deconditioned patients), aerobic training intensities as low as $40 \%$ of $\mathrm{VO}_{2}$ peak have proven to be effective and safe [71].

\section{High intensity interval training}

The concept of high intensity interval training (HIIT) was developed across several decades [72,73]. Basically, HIIT was conceived on the possibility of intensifying the action of the traning throughtout the increase on exercise intensity and decrease on exercise duration (short bouts of high intensity exercise) interpolated by short periods of rest or low-intensity exercise. The rationale behind HIIT is that the total amount of high-intensity exercise is higher than could be attained during a single bout of continuos exercise at the same intensity until to their maximum or even supra-maximum effort, the active recovery could be better [72,73].

About 20 years ago, Meyer et al. [74] compared the effects of 3 -week HIIT $v s$ activity restriction in 18 patients with severe HF. The HIIT protocol consisted of 30/60 second work/recovery intervals at respectively $50 \%$ of maximal short-term exercise capacity and 15 watts, during 15 minuts, 5 times/week. Authors reported $24 \%$ increase in $\mathrm{VO}_{2}$ peak [74] and a $6.5 \%$ improvement in 6-minute walk test distance [75] in the HIIT group.

Since then, a number of small single-center RCTs comparing HIIT to moderate-intensity continous ET have been performed [76-85]. In 2007, Wisloff et al. [76] compared the effect of HIIT [4-min training intervals at high intensity (90-95\% of peak heart rate), separated by 3 -min active pauses (walking at $50-70 \%$ of peak heart rate), total exercise time $38 \mathrm{~min}$, three times per week], with moderate-intensity continuous ET [walking continuously at 70-75\% of peak heart rate, for 47 min]. In a cohort of 27 post ischemic HF patients aged $75 \pm 11$ years and with mean LVEF of $29 \%$, the Authors observed that HIIT led to greater improvements in aerobic capacity $\left(\mathrm{VO}_{2}\right.$ peak increase of $46 \%$ vs. $14 \%$ in HIIT group, $\mathrm{p}<0.001$ ), reverse left ventricular remodelling, endothelial function and quality of life. These impressive findings have generated a wave of enthusiasm among the cardiac rehabilitation community. In addition, other studies reported the benefits of HIIT in HF patients [77-95]. Using similar protocols (3/3 minutes work/recovery intervals at respectively $80 \%$ and $40 \%$ of peak power output), Wang et al. [75] demonstrated a $23 \%$ increase in $\mathrm{VO}_{2}$ peak in the HIIT group compared to non significant changes in the moderate-countinous ET group $(p<0.05)$. Ventilatory efficiency and cardiac output were also significantly increased in the HIIT group compared to moderate-countinous ET group. After 16 weeks of stationary bike three times/week, Smart et al. [77] described comparable improvements in $\mathrm{VO}_{2}$ peak (respectively $21 \%$ and $13 \%$ in the HIIT and moderate-countinous ET groups). Of note, no significant changes in left ventricular dimensions or systolic/diastolic function were detected [77]. Finally, in shorter but intensive intervention (6 times/week during 8-week program), Freyssin et al. demonstrated $22 \%$ of $\mathrm{VO}_{2}$ peak increase compared to only $2 \%$ increase in the moderate-countinous ET group [80].

Data from meta-analysis including patients with HF showed higher HIIT-induced increase in $\mathrm{VO}_{2}$ peak compared to other training modalities [86]. The 5 RCTs meta-analyzed included clinically stable patients with HF with reduced ejection fraction (mean LVEF 32\%), relatively young (mean age 61 years) and predominantly men (82\%) [79]. Of note, comparison of the effects of both HIIT and moderate continous ET on resting LVEF was inconclusive [86].

Smart et al. [87] analyzed a cohort of 446 patients: 212 completed HIIT, 66 only continuous ET, 59 completed combined HIIT and strength training and 109 sedentary controls. Compared to continous training, HIIT determined a significant increase in $\mathrm{VO}_{2}$ peak [87]. Interestingly, HIIT and strength training (combined) determined a superior effect on $\mathrm{VO}_{2}$ peak compared to HIIT alone [87]. In addition, in selected studies, HIIT improved ventilatory efficiency compared to controls or continous training [87].

A more recent meta-analysis reported significant improvements in peak $\mathrm{VO}_{2}$ after HIIT in HF patients [88]. Interestingly, in HF patients, there were no improvements when the intensity recovery was $\leq 40 \%$ of $\mathrm{VO}_{2}$ peak and the frequency of training was $\leq 2$ days/week. In addition, in HF patients, programs lasting $<12$ weeks did not significantly improve $\mathrm{VO}_{2}$ peak. These data support the needing of long-term exercisebased cardiac rehabilitation programs [89].

Hovewer, the superiority of HIIT over moderate-countinous training in improving cardiopulmonary functional capacity was not systemati- 
cally ascertained. Using an exercise protocol with 30/30 seconds work/recovery intervals at high intensity ( $100 \%$ of peak power output) and passive recovery, Dimopoulos et al. [78] reported a quite modest increase in $\mathrm{VO}_{2}$ peak in HIIT cohort compared to moderate-countinous training group [78]. Notably, a significant increase in heart rate recovery was exclusively reported in the moderate-countinous ET cohort suggesting a positive exercise-induced effect on autonomic function modulation [76]. These findings were in line with previous studies in post-infarction patients demonstrating a significant improvement in heart rate recovery after 3 to 6 months moderate-countinous ET programs [90-92].

Recently, by using a similar exercise intervention as described by Wisloff et al. [76] but with slightly lower intensities, Iellamo et al. [83] reported a $22 \%$ improvement in $\mathrm{VO}_{2}$ peak in both HIIT and moderatecountinous ET cohorts, while neither training modality influences left ventricular remodelling indexes or cardiac output. The same research team investigated the exercise-induced hormonal response in patients with $\mathrm{HF}$ founding that, although both training modalities had the same effect on V02peak, HIIT resulted in a greated exercise-induced anabolic response; hence, suggesting that the amount of hormonal response is related to the exercise intensity [83]. Similar results have been previously documented in healthy subjects in which the greater hormonal response has been ascribed to the higher mechanical and metabolic stimuli induced by HIIT [93,94].

The SMARTEX-HF study, a randomized multicentre trial, is currently recruiting HF patients comparing the efficacy and safety of HIIT versus continous aerobic ET [95]. The results of this trial are eagerly awaited since they are expected to provide a more solid basis for future recommendations on training modalities.

Reported data on safety of HIIT in cardiac patients (however not exclusively HF patients) showed that the risk of a cardiovascular event is even lower after both HIIT and moderate-intensity ET in cardiovascular rehabilitation setting [96], even after acute decompensation [97]. A recent systematic review evaluating the safety of acute HIIT in patients with cardiometabolic diseases reported that the incidence of adverse responses during or within 24-hours after HIIT in patients with cardiometabolic diseases is around $8 \%$, which is slightly higher compared to the previously reported risk during moderate-continuous ET [98]. These findings indicate that patients who wish to perform HIIT should be clinically stable, have had recent exposure to at least regular moderate-intensity exercise, and appropriate supervision and monitoring during and after the exercise session are mandatory [98].

\section{Inspiratory muscle training}

In patients with $\mathrm{HF}$, inspiratory muscle weakness and peripheral skeletal muscle dysfunction may underlie fatigue, dyspnea, and exercise intolerance. Structural and biochemical alterations of the diaphragm muscle have been reported, including increased proportion of type I fibers, reduced type IIb fibers, and fiber atrophy due to chronic increase in diaphragm load and systemic myopathy [99-101].

Inspiratory muscle strength is assessed by maximal inspiratory pressure (PImax). It is measured at the mouth level by asking the subject taking a maximal inspiration while at residual volume and sustained for at least one second. According to the force-length relationship, the higher the position of the diaphragm (the longer the resting length of the diaphragm, or the lower the lung volume), the higher the PImax. This measure is independent of the patient's respiratory flow and is highly reproducible.

In patients with HF, PImax lower than $70 \%$ of the predicted value indicates respiratory muscle weakness [102]. Inspiratory muscle en- durance refers to the ability to sustain a certain respiratory pressure over time which can be measured asking the subject to sustain the PImax over time in order to obtain the sustained maximal inspiratory pressure [103-105]; otherwise measuring the highest pressure that the subject can maintain for at least one minute (Pth max) [102].

Inspiratory muscle training is beneficial for patients with HF. The benefits include increased inspiratory muscle strength, increased inspiratory endurance, improved exercise capacity, reduced dyspnea, and improved quality of life. The effect sizes were considered adequate for improvements of respiratory muscle strength, functional exercise capacity, and reduction of dyspnea [106,107].

Of great interest is the "aerobic/resistance/inspiratory (ARIS) muscle training hypothesis in HF, which is based on the decoding of the 'skeletal muscle hypothesis in HF' and on revision of experimental evidence showing that exercise and functional impairment in HF patients are not only associated with reduced muscle endurance, a clear indication for aerobic training; but also with reduced muscle strength and impaired inspiratory muscle function leading to dyspnea, fatigue, weakness, and low aerobic capacity, at the basis of the indication for adding both resistance and inspiratory muscle training to aerobic training [108]. Lautaris postulated that combined ARIS muscle training might result in maximal exercise pathophysiological and functional benefits in patients with HF [108]. The hypothesis will be tested by comparing all potential exercise combinations, ARIS, aerobic vs resistance training, aerobic $v s$ inspiratory muscle training, aerobic training alone, evaluating both functional and cardiac indices in a large sample of HF patients (Aerobic Resistance, InSpiratory Training OutcomeS in Heart Failure, ARISTOS-HF trial).

\section{Conclusions}

In patients with $\mathrm{HF}$, exercise training exerts large improvements in cardiopulmonary capacity, mostly when different training modalities are combined. Since better functional capacity always translates into symptoms relief and QoL improvement, these results are intriguing for cardiac rehabilitation community. Further studies should be designed in order to establish the best strategy in terms of type, duration, frequency and intensity of ET programs. A demanding challenge will be translating these protocols to HF patients with relevant comorbidity (i.e., frailty), after cardiac surgery or with advanced age.

\section{References}

1. Mendez GF, Cowie MR. The epidemiological features of heart failure in developing countries: a review of the literature. Int J Cardiol 2001;80:213-9.

2. Ferrucci L, Giallauria F, Guralnik JM. Epidemiology of Aging. Radiol Clin North Am 2008; 46: 43-652.

3. Piepoli MF, Hoes AW, Agewall S, et al. 2016 European Guidelines on cardiovascular disease prevention in clinical practice: The Sixth Joint Task Force of the European Society of Cardiology and Other Societies on Cardiovascular Disease Prevention in Clinical Practice (constituted by representatives of 10 societies and by invited experts) Developed with the special contribution of the European Association for Cardiovascular Prevention \& Rehabilitation (EACPR). Eur Heart J 2016;37:2315-81.

4. Corrà U, Giannuzzi P, Adamopoulos S, et al. Executive summary of the position paper of the Working Group on Cardiac Rehabilitation and Exercise Physiology of the European Society of Cardiology (ESC): core components of cardiac rehabilitation in chronic heart failure. Eur J Cardiovasc Prev Rehabil 2005;12:321-5. 
5. Harjola V, Mullens W, Banaszewski M, et al. Organ dysfunction, injury and failure in acute heart failure: from pathophysiology to diagnosis and management. A review on behalf of the Acute Heart Failure Committee of the Heart Failure Association (HFA) of the European Society of Cardiology (ESC). Eur J Heart Fail 2017;19:821-36.

6. Priori SG, Blomström-Lundqvist C, Mazzanti A, et al. 2015 ESC Guidelines for the management of patients with ventricular arrhythmias and the prevention of sudden cardiac death: The Task Force for the Management of Patients with Ventricular Arrhythmias and the Prevention of Sudden Cardiac Death of the European Society of Cardiology (ESC)Endorsed by: Association for European Paediatric and Congenital Cardiology (AEPC). Eur Heart J 2015;36:2793-867.

7. Giallauria F, Vigorito C, Piepoli MF, et al. Effects of cardiac contractility modulation by non-excitatory electrical stimulation on exercise capacity and quality of life: an individual patient's data metaanalysis of randomised controlled trials. Int J Cardiol 2014;175:352-7.

8. Davies EJ, Moxham T, Rees K, et al. Exercise based rehabilitation for heart failure. Cochrane Database Syst Rev 2010;CD003331.

9. Fukuta H, Goto T, Wakami K, et al. Effects of drug and exercise intervention on functional capacity and quality of life in heart failure with preserved ejection fraction: A meta-analysis of randomized controlled trials. Eur J Prev Cardiol 2016;23:78-85.

10. Davidson PM, Cockburn J, Newton PJ, et al. Can a heart failurespecific cardiac rehabilitation program decrease hospitalizations and improve outcomes in high-risk patients? Eur J Cardiovasc Prev Rehabil 2010;17:393-402.

11. Davies EJ, Moxham T, Rees K, et al. Exercise training for systolic heart failure: Cochrane systematic review and meta-analysis. Eur J Heart Fail 2010;12:706-15.

12. Giannuzzi P, Temporelli PL, Marchioli R, et al. Global secondary prevention strategies to limit event recurrence after myocardial infarction. Arch Intern Med 2008;168:2194-204.

13. Giallauria F, Galizia G, Lucci R, et al. Favourable effects of exercise-based cardiac rehabilitation after acute myocardial infarction on left atrial remodelling. Int J Cardiol 2009;136:300-6.

14. Giallauria F, Acampa W, Ricci F, et al. Effects of exercise training started within 2 weeks after acute myocardial infarction on myocardial perfusion and left ventricular function: a gated SPECT imaging study. Eur J Prev Cardiol 2012;19:1410-9.

15. Giallauria F, Acampa W, Ricci F, et al. Exercise training early after acute myocardial infarction reduces stress-induced hypoperfusion and improves left ventricular function. Eur J Nucl Med Mol Imaging 2013 40:315-24.

16. Dieberg G, Ismail H, Giallauria F, et al. Clinical outcomes and cardiovascular responses to exercise training in heart failure patients with preserved ejection fraction: a systematic review and meta-analysis. J Appl Physiol (1985) 2015;119:726-33.

17. Guazzi M, Myers J, Peberdy MA, et al. Echocardiography with tissue Doppler imaging and cardiopulmonary exercise testing in patients with heart failure: a correlative and prognostic analysis. Int J Cardiol 2010;143:323-9.

18. Kraigher-Krainer E, Shah AM, Gupta DK, et al. Impaired systolic function by strain imaging in heart failure with preserved ejection fraction. J Am Coll Cardiol 2014;63:447-56.

19. Bursi F, Weston SA, Redfield MM, et al. Systolic and diastolic heart failure in the community. JAMA 2006;296:2209-16.

20. Mosca S, Paolillo S, Colao A, et al. Cardiovascular involvement in patients affected by acromegaly: an appraisal. Int J Cardiol 2013;167:1712-8.

21. Bossone E, Lyon A, Citro R, et al. Takotsubo cardiomyopathy: an integrated multi-imaging approach. Eur Heart J Cardiovasc Imaging 2014;15:366-77.
22. Hatipoglu E, Topsakal N, Atilgan OE, et al. Impact of exercise on quality of life and body-self perception of patients with acromegaly. Pituitary 2014;17:38-43.

23. Saccà F, Piro R, De Michele G, et al. Epoetin alfa increases frataxin production in Friedreich's ataxia without affecting hematocrit. Mov Disord 2011;26:739-42.

24. Fillyaw MJ, Ades PA. Endurance exercise training in Friedreich ataxia. Arch Phys Med Rehabil 1989;70:786-8.

25. Giallauria F, Palomba S, Maresca L, et al. Exercise training improves autonomic function and inflammatory pattern in women with polycystic ovary syndrome (PCOS). Clin Endocrinol (Oxf) 2008;69:792-8.

26. Palomba S, Giallauria F, Falbo A, et al. Structured exercise training programme versus hypocaloric hyperproteic diet in obese polycystic ovary syndrome patients with anovulatory infertility: a 24-week pilot study. Hum Reprod 2008;23:642-50.

27. Orio F, Giallauria F, Palomba S, et al. Metabolic and cardiopulmonary effects of detraining after a structured exercise training programme in young PCOS women. Clin Endocrinol (Oxf) 2008;68:976-81.

28. Vigorito C, Giallauria F, Palomba S, et al. Beneficial effects of a three-month structured exercise training program on cardiopulmonary functional capacity in young women with polycystic ovary syndrome. J Clin Endocrinol Metab 2007;92:1379-84.

29. Piepoli MF, Guazzi M, Boriani G, et al. Exercise intolerance in chronic heart failure: mechanisms and therapies. Part I. Eur J Cardiovasc Prev Rehabil 2010;17:637-42.

30. Piepoli MF, Guazzi M, Boriani G, et al. Exercise intolerance in chronic heart failure: mechanisms and therapies. Part II. Eur J Cardiovasc Prev Rehabil 2010;176:643-8.

31. Gielen S, Schuler G, Adams V. Cardiovascular effects of exercise training: molecular mechanisms. Circulation 2010;122:1221-38.

32. Erbs S, Höllriegel R, Linke A, et al. Exercise training in patients with advanced chronic heart failure (NYHA IIIb) promotes restoration of peripheral vasomotor function, induction of endogenous regeneration, and improvement of left ventricular function. Circ Heart Fail 2010;3:486-94.

33. Passino C, Severino S, Poletti R, et al. Aerobic training decreases B-type natriuretic peptide expression and adrenergic activation in patients with heart failure. J Am Coll Cardiol 2006;47:1835-9.

34. Rengo G, Galasso G, Femminella GD, et al. Reduction of lymphocyte G protein-coupled receptor kinase-2 (GRK2) after exercise training predicts survival in patients with heart failure. Eur J Prev Cardiol 2014;21: 4-11.

35. Gielen S, Adams V, Möbius-Winkler S, et al. Anti-inflammatory effects of exercise training in the skeletal muscle of patients with chronic heart failure. J Am Coll Cardiol 2003;42:861-8.

36. Giallauria F, Cirillo P, D’Agostino M, et al. Effects of exercise training on high mobility group box-1 levels after acute myocardial infarction. J Cardiac Fail 2011;17:108-14.

37. Vega RB, Konhilas JP, Kelly DP, Leinwand LA. Molecular mechanisms underlying cardiac adaptation to exercise. Cell Metab 2017;25:1012-26.

38. Rengo G, Parisi V, Femminella GD, et al. Molecular aspects of the cardioprotective effect of exercise in the elderly. Aging Clin Exp Res 2013;25:487-97.

39. Smart NA, Meyer T, Butterfield JA, et al. Individual patient metaanalysis of exercise training effects on systemic brain natriuretic peptide expression in heart failure. Eur J Prev Cardiol 2012;19:428-35.

40. Giallauria F, Cirillo P, Lucci R, et al. Left ventricular remodelling in patients with moderate systolic dysfunction after myocardial infarction: favourable effects of exercise training and predictive role of $\mathrm{N}$-terminal pro-Brain natriuretic peptide. Eur J Cardiovasc Prev Rehabil 2008;15:113-8. 
41. Giallauria F, De Lorenzo A, Pilerci F, et al. Reduction of NT-proBNP levels with exercise-based cardiac rehabilitation in patients with left ventricular dysfunction after myocardial infarction. Eur J Cardiovasc Prev Rehabil 2006;13:625-632.

42. Giallauria F, Lucci R, De Lorenzo A, et al. Favourable effects of exercise training on $\mathrm{N}$-terminal pro-Brain natriuretic peptide plasma levels in elderly patients after acute myocardial infarction. Age Ageing 2006;35:601-7.

43. Hambrecht R, Adams V, Erbs S, et al. Regular physical activity improves endothelial function in patients with coronary artery disease by increasing phosphorylation of endothelial nitric oxide synthase. Circulation 2003;107:3152-8.

44. Cittadini A, Monti MG, Iaccarino G, et al. SOCS1 gene transfer accelerates the transition to heart failure through the inhibition of the gp130/JAK/STAT pathway. Cardiovasc Res 2012;96:381-90.

45. Cittadini A, Monti MG, Castiello MC, et al. Insulin-like growth factor-1 protects from vascular stenosis and accelerates reendothelialization in a rat model of carotid artery injury. J Thromb Haemost 2009;7:1920-8.

46. Arcopinto M, Salzano A, Bossone E, et al. Multiple hormone deficiencies in chronic heart failure. Int J Cardiol 2015;184:421-3.

47. Fazio S, Palmieri EA, Affuso F, et al. Effects of growth hormone on exercise capacity and cardiopulmonary performance in patients with chronic heart failure. J Clin Endocrinol Metab 2007;92:4218-23.

48. Cittadini A, Marra AM, Arcopinto M, et al. Growth hormone replacement delays the progression of chronic heart failure combined with growth hormone deficiency: an extension of a randomized controlled single-blind study. JACC Heart Fail 2013;1:325-30.

49. Keteyian SJ, Kerrigan DJ, Lewis B, et al. Exercise training workloads in cardiac rehabilitation are associated with clinical outcomes in patients with heart failure. Am Heart J 2018;204:76-82.

50. Taylor RS, Davies EJ, Dalal HM, et al. Effects of exercise training for heart failure with preserved ejection fraction: A systematic review and metaanalysis of comparative studies. Int $\mathrm{J}$ Cardiol 2012;162:6-13.

51. Obert P, Mandigout S, Vinet A, et al. Effect of aerobic training and detraining on left ventricular dimensions and diastolic function in prepubertal boys and girls. Int J Sports Med 2001;22:90-6.

52. Palau P, Dominguez E, Nunez E, et al. Effects of inspiratory muscle training in patients with heart failure with preserved ejection fraction. Eur J Prev Cardiol 2014;21:1465-73.

53. Piepoli MF, Davos C, Francis DP, et al. Exercise training meta-analysis of trials in patients with chronic heart failure (ExTraMATCH). BMJ 2004;328: 89.

54. Smart N, Marwick TH. Exercise training for patients with heart failure: a systematic review of factors that improve mortality and morbidity. Am J Med 2004;116:693-706.

55. O'Connor CM, Whellan DJ, Lee KL, et al. Efficacy and safety of exercise training in patients with chronic heart failure: HF-ACTION randomized controlled trial. JAMA 2009;301:1439-50.

56. Karmali KN, Davies P, Taylor F, et al. Promoting patient uptake and adherence in cardiac rehabilitation. Cochrane Database Syst Rev 2014;CD007131.

57. Resurrección DM, Moreno-Peral P, Gómez-Herranz M, et al. Factors associated with non-participation in and dropout from cardiac rehabilitation programmes: a systematic review of prospective cohort studies. Eur J Cardiovasc Nurs 2018: 1474515118783157. doi: 10.1177/1474515118783157. [Epub ahead of print]

58. Piepoli MF, Conraads V, Corrà U, et al. Exercise training in heart failure: from theory to practice. A consensus document of the Heart Failure Association and the European Association for
Cardiovascular Prevention and Rehabilitation. Eur J Heart Fail 2011;13:347-57.

59. Vanhees L, Schepers D, Heidbüchel H, et al. Exercise performance and training in patients with implantable cardioverter-defibrillators and coronary heart disease. Am J Cardiol 2001;87: 12-5.

60. Taylor RS, Sagar VA, Davies EJ, et al. Exercise-based rehabilitation for heart failure. Cochrane Database Syst Rev 2014;CD003331.

61. Binder RK, Wonisch M, Corra U, et al. Methodological approach to the first and second lactate threshold in incremental cardiopulmonary exercise testing. Eur J Cardiovasc Prev Rehabil 2008;15:726-34.

62. Meyer T, Lucía A, Earnest CP, et al. A conceptual framework for performance diagnosis and training prescription from submaximal gas exchange parameters - theory and application. Int J Sports Med 2005;26(Suppl 1):S38-48.

63. Kervio G, Ville NS, Leclercq C, et al. Cardiorespiratory adaptations during the six-minute walk test in chronic heart failure patients. Eur J Cardiovasc Prev Rehabil 2004;11:171-7.

64. Ingle L, Witte KK, Cleland JG, et al. The prognostic value of cardiopulmonary exercise testing with a peak respiratory exchange ratio of $<1.0$ in patients with chronic heart failure. Int J Cardiol 2008;127:88-92.

65. Corrà U, Mezzani A, Giordano A, et al. A new cardiopulmonary exercise testing prognosticating algorithm for heart failure patients treated with beta-blockers. Eur J Prev Cardiol 2012;19:185-91.

66. Mezzani A, Corrà U, Giordano A, et al. Upper intensity limit for prolonged aerobic exercise in chronic heart failure. Med Sci Sports Exerc 2010;42:633-9.

67. Mezzani A, Hamm LF, Jones AM, et al. Aerobic exercise intensity assessment and prescription in cardiac rehabilitation: a joint position statement of the European Association for Cardiovascular Prevention and Rehabilitation, the American Association of Cardiovascular and Pulmonary Rehabilitation and the Canadian Association of Cardiac Rehabilitation. Eur J Prev Cardiol 2013;20:442-67.

68. Mezzani A, Agostoni P, Cohen-Solal A, et al. Standards for the use of cardiopulmonary exercise testing for the functional evaluation of cardiac patients: a report from the Exercise Physiology Section of the European Association for Cardiovascular Prevention and Rehabilitation. Eur J Cardiovasc Prev Rehabil 2009;16:249-67.

69. Carvalho VO. Aerobic exercise prescription in patients with chronic heart failure: a review in the beta-blocker era. J Cardiovasc Med (Hagerstown) 2012;13:570-4.

70. Mezzani A, Grassi B, Jones AM, et al. Speeding of pulmonary V02 on-kinetics by light-to-moderate-intensity aerobic exercise training in chronic heart failure: clinical and pathophysiological correlates. Int J Cardiol 2013;167:2189-95.

71. Belardinelli R, Georgiou D, Scocco V, et al. Low intensity exercise training in patients with chronic heart failure. J Am Coll Cardiol 1995;26:975-82.

72. Meyer P, Gayda M, Juneau M, et al. High-intensity aerobic interval exercise in chronic heart failure. Curr Heart Fail Rep 2013;10:130-8.

73. Carvalho V0, Mezzani A. Aerobic exercise training intensity in patients with chronic heart failure: principles of assessment and prescription. Eur J Cardiovasc Prev Rehabil 2011;18:5-14.

74. Meyer K, Schwaibold M, Westbrook S, et al. Effects of short-term exercise training and activity restriction on functional capacity in patients with severe chronic congestive heart failure. Am J Cardiol 1996;78:1017-22.

75. Meyer K, Schwaibold M, Westbrook S, et al. Effects of exercise training and activity restriction on 6-minute walking test performance in patients with chronic heart failure. Am Heart $\mathrm{J}$ 1997;133:447-53. 
76. Wisløff U, Støylen A, Loennechen JP, et al. Superior cardiovascular effect of aerobic interval training versus moderate continuous training in heart failure patients: a randomized study. Circulation 2007;115:3086-94.

77. Smart NA, Steele M. A comparison of 16 weeks of continuous vs intermittent exercise training in chronic heart failure patients. Congest Heart Fail 2012;18:205-11.

78. Dimopoulos S, Anastasiou-Nana M, Sakellariou D, et al. Effects of exercise rehabilitation program on heart rate recovery in patients with chronic heart failure. Eur J Cardiovasc Prev Rehabil 2006;13:67-73.

79. Roditis P, Dimopoulos S, Sakellariou D, et al. The effects of exercise training on the kinetics of oxygen uptake in patients with chronic heart failure. Eur J Cardiovasc Prev Rehabil 2007;14:304-11.

80. Freyssin C, Verkindt C, Prieur F, et al. Cardiac rehabilitation in chronic heart failure: effect of an 8-week, high-intensity interval training versus continuous training. Arch Phys Med Rehabil 2012;93:1359-64.

81. Rognmo Ø, Moholdt T, Bakken H, et al. Cardiovascular risk of high- versus moderate-intensity aerobic exercise in coronary heart disease patients. Circulation 2012;126:1436-40.

82. Wang JS, Fu TC, Lien HY, et al. Effect of aerobic interval training on erythrocyte rheological and hemodynamic functions in heart failure patients with anemia. Int J Cardiol 2013;168:1243-50.

83. Iellamo F, Manzi V, Caminiti G, et al. Matched dose interval and continuous exercise training induce similar cardiorespiratory and metabolic adaptations in patients with heart failure. Int J Cardiol 2013;167:2561-5.

84. Caminiti G, Iellamo F, Manzi V, et al. Anabolic hormonal response to different exercise training intensities in men with chronic heart failure. Int J Cardiol 2014;176:1433-4.

85. Koufaki P, Mercer TH, George KP, et al. Low-volume high-intensity interval training vs continuous aerobic cycling in patients with chronic heart failure: a pragmatic randomised clinical trial of feasibility and effectiveness. J Rehabil Med 2014;46:348-56.

86. Haykowsky MJ, Timmons MP, Kruger C, et al. Meta-analysis of aerobic interval training on exercise capacity and systolic function in patients with heart failure and reduced ejection fractions. Am J Cardiol 2013;111:1466-9.

87. Smart NA, Dieberg G, Giallauria F. Intermittent versus continuous exercise training in chronic heart failure: a meta-analysis. Int J Cardiol 2013;166:352-8.

88. Ballesta García I, Rubio Arias JÁ, Ramos Campo DJ, et al. Highintensity interval training dosage for heart failure and coronary artery disease cardiac rehabilitation. A systematic review and meta-analysis. Rev Esp Cardiol (Engl Ed) 2018. pii: S18855857(18)30073-2.

89. Giallauria F, Lucci R, D’Agostino M, et al. Two-year multicomprehensive secondary prevention program: favorable effects on cardiovascular functional capacity and coronary risk profile after acute myocardial infarction. J Cardiovasc Med (Hagerstown) 2009;10:772-80.

90. Giallauria F, Lucci R, Pietrosante M, et al. Exercise-based cardiac rehabilitation improves heart rate recovery in elderly patients after acute myocardial infarction. J Gerontol Ser A-Biol Sci Med Sci 2006;61:713-7.

91. Giallauria F, De Lorenzo A, Pilerci F, et al. Long-term effects of cardiac rehabilitation on end-exercise heart rate recovery after myocardial infarction. Eur J Cardiovasc Prev Rehabil 2006;13:544-50.

92. Giallauria F, Cirillo P, Lucci R, et al. Autonomic dysfunction is associated with high mobility group box-1 levels in patients after acute myocardial infarction. Atherosclerosis 2010;208:280-4.

93. Hackney AC, Hosick KP, Myer A, et al. Testosterone responses to intensive interval versus steady-state endurance exercise. J Endocrinol Invest 2012;35:947-50.

94. Giannoulis MG, Boroujerdi MA, Powrie J, et al. Gender differences in growth hormone response to exercise before and after rhGH administration and the effect of rhGH on the hormone profile of fit normal adults. Clin Endocrinol (Oxf) 2005;62:315-22.

95. Støylen A, Conraads V, Halle M, et al. Controlled study of myocardial recovery after interval training in heart failure: SMARTEX-HFrationale and design. Eur J Prev Cardiol 2012;19:813-21.

96. Wisløff U, Ellingsen $\emptyset$, Kemi 0J. High-intensity interval training to maximize cardiac benefits of exercise training? Exerc Sport Sci Rev 2009;37:139-46.

97. Doletsky A, Andreev D, Giverts I, et al. Interval training early after heart failure decompensation is safe and improves exercise tolerance and quality of life in selected patients. Eur J Prev Cardiol 2018;25:9-18.

98. Levinger I, Shaw CS, Stepto NK, et al. What doesn't kill you makes you fitter: A systematic review of high-intensity interval exercise for patients with cardiovascular and metabolic diseases. Clin Med Insights Cardiol 2015;9:53-63.

99. Stassijns G, Lysens R, Decramer M. Peripheral and respiratory muscles in chronic heart failure. Eur Respir J 1996;9:2161-7.

100. Tikunov B, Levine S, Mancini D. Chronic congestive heart failure elicits adaptations of endurance exercise in diaphragmatic muscle. Circulation 1997;95:910-6.

101. Wong E, Selig S, Hare DL. Respiratory muscle dysfunction and training in chronic heart failure. Heart Lung Circ 2011;20:289-94.

102. Dall'Ago $\mathrm{P}$, Chiappa GR, Guths $\mathrm{H}$, et al. Inspiratory muscle training in patients with heart failure and inspiratory muscle weakness: A randomized trial. J Am Coll Cardiol 2006;47:757-63.

103. Laoutaris ID, Dritsas A, Brown MD, et al. Immune response to inspiratory muscle training in patients with chronic heart failure. Eur J Cardiovasc Prev Rehabil 2007;14:679-85.

104. Laoutaris ID, Dritsas A, Adamopoulos S, et al. Effects of inspiratory muscle training in patients with chronic heart failure. J Am Coll Cardiol 2008;52:1888-9.

105. Laoutaris ID, Dritsas A, Brown MD, et al. Effects of inspiratory muscle training on autonomic activity, endothelial vasodilator function, and N-terminal pro-brain natriuretic peptide levels in chronic heart failure. J Cardiopulm Rehabil Prev 2008;28:99-106.

106. Smart NA, Giallauria F, Dieberg G. Efficacy of inspiratory muscle training in chronic heart failure patients: a systematic review and meta-analysis. Int J Cardiol 2013;167:1502-7.

107. Gomes Neto M, Ferrari F, Helal L, et al. The impact of highintensity inspiratory muscle training on exercise capacity and inspiratory muscle strength in heart failure with reduced ejection fraction: a systematic review and meta-analysis. Clin Rehabil 2018 doi: 10.1177/0269215518784345. [Epub ahead of print].

108. Laoutaris ID. The 'aerobic/resistance/inspiratory muscle training hypothesis in heart failure'. Eur J Prev Cardiol 2018;25:1257-62. 